DOI: 10.15587/2706-5448.2021.231465

Article type «Reports on Research Projects»

\section{Andrii Markevych, Volodymyr Vdovychenko, Igor Ivanov}

\title{
INFLUENCE OF BUS SERVICE DOWNTIME IN THE TRANSPORT INTERCHANGE ON THE DURATION OF INTER-ROUTE TRANSFER OF PASSENGERS
}

The object of the study is the effect of the downtime of vehicles at stopping points on the duration of the route between passengers within the transport hub. As a controllable parameter that determines the conditions for synchronizing the presence of vehicles at stopping points and reproduces the characteristic effect on the weighted average time spent by passengers in transport hubs, the time of additional service downtime of vehicles is allocated. The simulation modeling and processing of the results obtained made it possible to establish the characteristic patterns of changes in the time spent by passengers in transport hubs for two types of routes with different volumes of passenger arrivals, the proportion of inter-route transfers and the interval of movement. It was found that for routes with scheduled arrivals more than 40 passengers and the specific gravity of inter-route transfers up to $45 \%$, the introduction of additional service downtime does not allow a positive effect on the duration of the stay of passengers in transport hubs. The implementation of service downtime is advisable for routes with an average volume of regular arrivals of passengers (up to 40 passengers) and a specific weight of inter-route transfers of more than $45 \%$. For such conditions, the regularities are described by a third-degree polynomial with the available characteristic period, which minimizes the function of the time spent by passengers. On the basis of the conducted experimental studies, it has been established that for routes with a specific gravity of a change from $45 \%$ to $59 \%$, it is advisable to have a service downtime in the range of 1 minute up to 3 minutes, and for routes with a transfer rate of more than $59 \%$ - within 2 minutes up to 5 minutes. The use of service downtime will increase the effectiveness of the synchronization of inter-route transfers in conditions of stochastic traffic and reduce the time spent by passengers in the transport interchange hub by 0.9-3.9 minutes (14-38\%) in comparison with the existing organization of interaction between the subjects of the route flow.

Keywords: urban passenger transport, stopping point, service downtime, inter-route transfer.

\section{How to cite}

Markevych, A., Vdovychenko, V., Ivanov, I. (2021). Influence of bus service downtime in the transport interchange on the duration of inter-route transfer of passengers. Technology Audit and Production Reserves, 3 (2 (59)), 41-45. doi: http://doi.org/10.15587/2706-5448.2021.231465

\section{Introduction}

In modern conditions of development of urban areas, acute problems acquire the issues of ensuring high-quality and safe mobility of the population. An effective way to ensure the mobility of the urban population in the conditions of compliance with the requirements for reducing negative consequences and ensuring resource conservation is the spread of the use of urban passenger transport (UPT). The main requirement for the UPT transport service, which is an important characteristic of the social development of cities, is to reduce the time spent on travel, which is one of the characteristics of the quality of transport services for the population [1]. An important element of UPT is transport interchange hubs (TIH), which, next to high-speed transport highways, is the fundamental frame of its network. The state of the organization of technological processes in TIHs largely determines the conditions for using the UPT potential and, along with the task of stabilizing the movement of route transport from the road network, is very relevant today [2].

Analysis of the technological process taking place in TIH showed the lack of a clear planning of the duration of the service downtime of vehicles at stopping points. Under such conditions, the presence of vehicles in TIH is chaotic, which largely makes it impossible for passengers to plan inter-route transfers and leads to an increase in the time spent on them.

To a large extent, the situation with the TIH operation is aggravated by the lack of a clear understanding of the impact of the duration of technological operations at stopping points (SP) on the time of inter-route passenger transfers. The existing approaches to the establishment of time parameters for the location of vehicles at stopping 
points have a number of disadvantages, primarily associated with the lack of consideration of the conditions for interroute transfers. So, in [3], the residence time is determined based on the requirements to ensure full passenger traffic of vehicles without taking into account the limitations of the throughput of stopping points. In [4], the duration of downtime is associated with the conditions for collecting fares, while also not taking into account the peculiarities of the formation of incoming passenger traffic. The approach proposed in [5] to assessing the effectiveness of the interaction of the route flow in the SP is based on taking into account the conditions for the occurrence of conflict situations, but does not take into account the possibility of synchronizing the moments of the implementation of interroute transfers. In [6], the waiting time of passengers for boarding is determined on the basis of the mathematical expectation of the average interval of vehicle arrival. This approach can only be used for stopping points with one route. The method proposed in [7] for calculating the time parameters of movement through stopping points aimed at establishing the throughput of infrastructure elements. Among the ways to reduce the time of inter-route transfer, methods of synchronizing the moments of arrival of vehicles to TIH have become widespread [8-10]. Also in this direction it is possible to consider the approaches to the architectural and planning coordination of the SP placement [11, 12]. However, the effectiveness of the presented approaches in relation to reducing the time of inter-route transfers is achieved only under the condition of strict adherence to the traffic schedule, which is possible only if separate traffic lanes are allocated for UPT. In the conditions of stochastic arrival of vehicles to TIH, reducing the time of inter-route transfer is possible by expanding the range of their stay in the SP by introducing additional service downtime. However, the introduction of additional downtime can have negative consequences on the performance of the rolling stock of the UPT and should be justified from the standpoint of technological feasibility in relation to the duration of the inter-route transfer.

So, the object of research is the effect of the duration of the additional service downtime of vehicles at the stopping point on the time of inter-route transfers of passengers in TIH. The aim of research is to establish the characteristic effect of the duration of additional service downtime of vehicles at stopping points, the conditions for synchronization of inter-route transfers, which determine the time spent by passengers in TIH.

\section{Methods of research}

A prerequisite for reducing the duration of interroute transfers is to ensure synchronization of the simultaneous stay of vehicles in TIH. In the conditions of stochasticity of motor processes on route sections, this can be achieved by introducing additional service downtime. Service downtime allows to expand the range of the vehicle's stay in TIH, thereby ensuring the transfer of passengers between routes without waiting. Fig. 1 shows a graphical interpretation of the process of inter-route transfer of passengers in $\mathrm{TIH}$ for the conditions of synchronization of the time spent by vehicles of two routes.

The process of inter-route transfer of passengers is determined by the time parameters of the ope- rations carried out by the vehicle in the SP. At the moment of time $\tau_{a r}^{1 f w}$, the vehicles of the first route $r_{1}^{f w}$ arrive at the TIH, and at the moment $\tau_{a r}^{2 f w}$ - vehicle of the second route $r_{2}^{f w}$. According to the program for coordinating the timetable for the arrival of the vehicle of the second route, it should have occurred at a time $\tau_{a p}^{2 f w}$ that, under synchronization conditions, should coincide with $\tau_{a r}^{1 f w}$. However, due to traffic delays, there is a delay in arrival for a period $\tau_{a p}^{2 f w}-\tau_{a r}^{2 f w}$. The vehicle of the first route leaves the TIH at the moment $\tau_{a d}^{1 f w}$, which is located earlier than the vehicle of the second route arrives. Under such conditions, the transfer of passengers in the direction $r_{2}^{f w}-r_{1}^{f w}$ is possible only for the next flight of the route $r_{1}^{f w}$, which will arrive in time, which is almost equal to the interval of movement on the route. This leads to a rapid increase in the time spent on the transit route of passengers. It is possible to ensure the simultaneous presence of the vehicle of both routes in TIH by introducing additional service downtime. This time is intended to compensate for deviations in the schedule. If an additional period $\tau_{a d}^{1 f w}-\tau_{d p}^{1 f w}$ is added to the technological downtime of the vehicle $r_{1}^{f w}$ associated with ensuring the boarding and unboarding of passengers, the time spent in TIH is extended. This makes it possible to realize the simultaneous presence of the vehicle of both routes during the period $\tau_{a r}^{2 f w}-\tau_{d p}^{1 f w}$ during which passenger transfer routes are carried out without waiting.

An additional service downtime is determined for the vehicle, arriving first in the TIH. The duration of the service downtime required to synchronize the time spent by the vehicle in the TIH is calculated by the formula:

$$
t_{r 1}^{a d}=\max \left(0 ; \tau_{a r}^{2 f w}-\tau_{a r}^{1 f w}\right)+t_{r 2}^{d p}+t_{r 2}^{e x}+t_{s p_{2-1}}^{p}+t_{r 1}^{e n},
$$

where $t_{r 2}^{d p}$ - time of vehicle maneuvering of the route $r_{2}^{f w}$ when entering the SP, min; $t_{r 2}^{e x}$ - time of unboarding of passengers arriving on the route $r_{2}^{f w}$, min; $t_{s p_{2-1}}^{p}-$ time of transition between SP, min; $t_{r 1}^{e n}$ - time of boarding passengers on the route $r_{1}^{f w}$ vehicle arriving from the route $r_{2}^{f w}$, $\min$.

The time required for unboarding passengers arriving on the route $r_{2}^{f w}$ is determined based on the passenger traffic and the average unboarding time for one passenger:

$$
t_{r 2}^{e x}=q_{r 2}^{e x} \cdot \tau_{p}^{e x},
$$

where $q_{r 2}^{e x}$ - volume of passengers leaving the vehicle of the route $r_{2}^{f w}$, passengers; $\tau_{p}^{e x}-$ average unboarding time of a passenger from the vehicle, min.

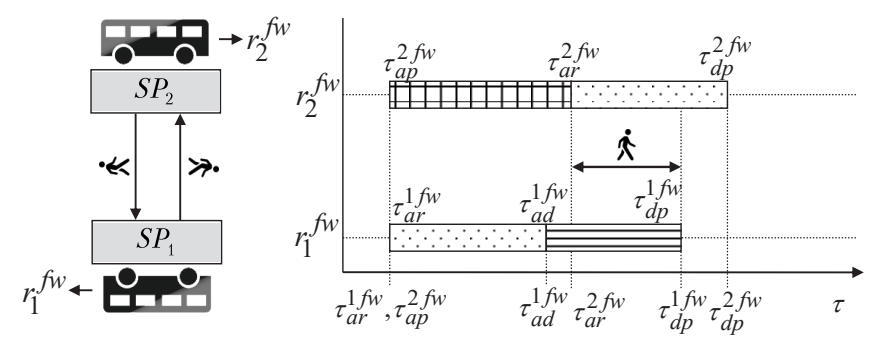

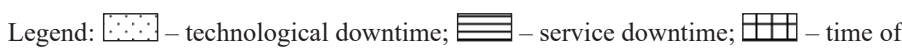
departure of the arrival of the vehicle

Fig. 1. Graphical interpretation of the process of inter-route transfer of passengers when synchronizing the location of vehicles in TIH 
The time required for boarding passengers on the route $r_{1}^{f w}$ vehicle arriving from the route $r_{2}^{f w}$ is determined based on the specific weight of the transfer, passenger traffic and the average boarding time for one passenger:

$$
t_{r 1}^{e n}=\varphi_{r 2}^{2-1} \cdot q_{r 2}^{e x} \cdot \tau_{p}^{e n}
$$

where $\varphi_{r 2}^{2-1}$ - proportion of passengers leaving the vehicle on the route $r_{2}^{f w}$ and transferring to the route $r_{1}^{f w} ; \tau_{p}^{e n}$ - average time of passenger boarding in the vehicle, min.

Vehicle maneuvering and the transition between stopping points are quantities that do not depend on the technological organization of the UPT operation in TIH. Their values are established on the basis of field observations.

The main disadvantages of implementing additional service downtime are a decrease in the productivity of the rolling stock on the route and an increase in the travel time of passengers who are in the vehicle and transit through TIH without boarding and unboarding. The decision on the advisability of introducing additional service downtime should be made on the condition that the weighted average time spent in TIH by passengers moving in transit and with a transfer will be reduced. The average time spent by a passenger in TIH is calculated using the formula:

$$
T_{r}^{s p}=\frac{\sum_{i=1}^{n_{s r}} T_{r i}^{s p} \cdot\left(\varphi_{r i}^{i-j} \cdot q_{r i}^{e x}+q_{r i}^{t r}\right)}{\sum_{i=1}^{n_{s r}}\left(\varphi_{r j}^{i} \cdot q_{r i}^{e x}+q_{r i}^{t r}\right)},
$$

where $T_{r i}^{s p}$ - average time spent by passengers in TIH arriving on the route $i$, min; $q_{r i}^{e x}$ - the number of passengers leaving the vehicle of the route $i$, passengers; $q_{r i}^{t r}-$ the number of passengers on the route $i$ passing TIH in transit, passengers; $n_{c r}$ - the number of routes on which the transfer is carried out.

The average time spent by passengers in TIH for the route $r_{2}^{f w}$ is calculated by the formula:

$$
T_{r 2-1}^{s p}=\frac{\varphi_{r 2}^{2-1} \cdot q_{r 2}^{e x} \cdot\left(\tau_{d p}^{1 f w}-\tau_{a r}^{2 f w}-t_{r 1,2}^{d p}-t_{r 1,2}^{e n}-t_{s p_{2-1}}^{p}\right)+q_{r 2}^{t r} \cdot\left(t_{r 2}^{d p}+t_{r 2}^{e n}+t_{r 2}^{a d}\right)}{\varphi_{r 2}^{2-1} \cdot q_{r 2}^{e x}+q_{r 2}^{t r}},
$$

where $t_{r 1(2)}^{d p}$ - time of vehicle maneuvers when entering and exiting $\mathrm{TIH}, \mathrm{min} ; t_{r 1(2)}^{e n}$ - time of opening and closing of vehicle doors, min.

The basis for establishing the influence of the service downtime of vehicles at a stopping point on the duration of inter-route transfer of passengers is the simulation of the process [13]. Based on the composition of the model for calculating the average time spent by passengers in $\mathrm{TIH}$, it can be determined that along with the duration of service downtime, it is influenced by the volume of passengers moving. Within the framework of the simulation experiment, two types of transfers were considered: with an average flight volume of arrival (up to 40 passengers) and a significant one (more than 40 passengers). For experimental studies, two pairs of routes for TIH were selected as basic types: «Heroiv Pratsi» station in Kharkiv (50.024616, 36.334937) and «Zaliznychna Street» station in Kherson (46.650216, 32.597849). The collection of primary information about the parameters of the input route flow was carried out using field observations. The total number of observations was 603 units. Subsequently, on their basis, the average values of the parameters and certain laws of distribution of random variables were established. The characteristic of the route flow is given in Table 1 .

Route flow characteristic

\begin{tabular}{|l|c|c|c|c|}
\hline \multicolumn{1}{|c|}{ Iindicator } & \multicolumn{2}{|c|}{ «Heraiv Pratsi» station } & \multicolumn{2}{|c|}{ "Zaliznychna Street» } \\
\hline Route number & No. 41 & No. 271 & No. 5 & № 16 \\
\hline $\begin{array}{l}\text { Average voyage of passenger } \\
\text { arrivals, passengers }\end{array}$ & 42 & 46 & 27 & 23 \\
\hline $\begin{array}{l}\text { Range of the route volume } \\
\text { of passenger transfers, pas- } \\
\text { sengers }\end{array}$ & $5-18$ & $3-16$ & $8-21$ & $9-20$ \\
\hline \begin{tabular}{l} 
Intensity, vehicle/hour \\
\hline Arrival interval, min
\end{tabular} & $8-10$ & $8-12$ & $12-17$ & $15-18$ \\
\hline Arrival interval distribution law & \multicolumn{3}{|c|}{ Lognormal distribution } \\
\hline $\begin{array}{l}\text { Average maneuvering time, s } \\
\text { Average passenger boarding- } \\
\text { unboarding time, s }\end{array}$ & \multicolumn{3}{|c|}{52} & 14 \\
\hline
\end{tabular}

The simulation procedure was implemented using the ModelingSP program, developed at the Department of Transport Technologies of the Kharkiv National Automobile and Highway University (Ukraine). In the course of simulation, 92 series of experiments were carried out for selected pairs of routes, in which the situation of the arrival of 1104 vehicles was simulated.

\section{Research results and discussion}

The experimental results obtained in the course of simulation modeling are the basis for establishing the patterns of changes in the time spent by passengers in TIH for the selected types of two pairs of routes. In addition to the additional service time, a simple characteristic effect on the duration of the stay of passengers in TIH is exerted by the structure of the distribution of the scheduled passenger traffic between transit movements and passengers making a transfer.

To establish the nature of such an influence, four variants of different volumes of inter-route transfers were considered, ranging from 3 up to 21 passengers. The implementation of the procedure for analyzing the results of experimental studies was carried out on the basis of a visual-graphical presentation. Fig. 2 shows the graphs of changes in the time spent by passengers in TIH for routes passing through TIH «Heroiv Pratsi» station.

Fig. 3 shows the graphs of changes in the time spent by passengers in TIH for routes passing through TIH «Zaliznychna street». The influence of the service downtime of passengers in TIH is manifested through the expansion of the synchronization range of the vehicle's stay at stopping points. For a pair of routes with a scheduled arrival volume of more than 40 passengers. and the specific gravity of inter-route transfers from $7 \%$ (3 passengers) to $17 \%$ (8 passengers), it was found that this influence is described by a linear function, and for the specific gravity from $17 \%$ (8 passengers) to $39 \%$ (18 passengers) - a polynomial of the second degree. At the same time, the dispersion of time values $T_{r}^{s p}$ is very small, which is explained by the main influence on it of the time spent in the vehicle by transit passengers. For all volumes of inter-route transfers, there is 
a tendency in which the average time spent by passengers in TIH $\left(T_{r i}^{s p}\right)$ increases with the introduction of additional service downtime $\left(t_{r 1}^{a d}\right)$. This is due to the basic conditions for the formation of synchronization, among which the interval of movement also plays an important role. For routes that are considered for TIH «Heroiv Pratsi» station is characterized by a small interval of movement (8-12 minutes). This leads to the fact that the reduction in time from synchronization of a simple vehicle is insignificant in relation to the average waiting time.
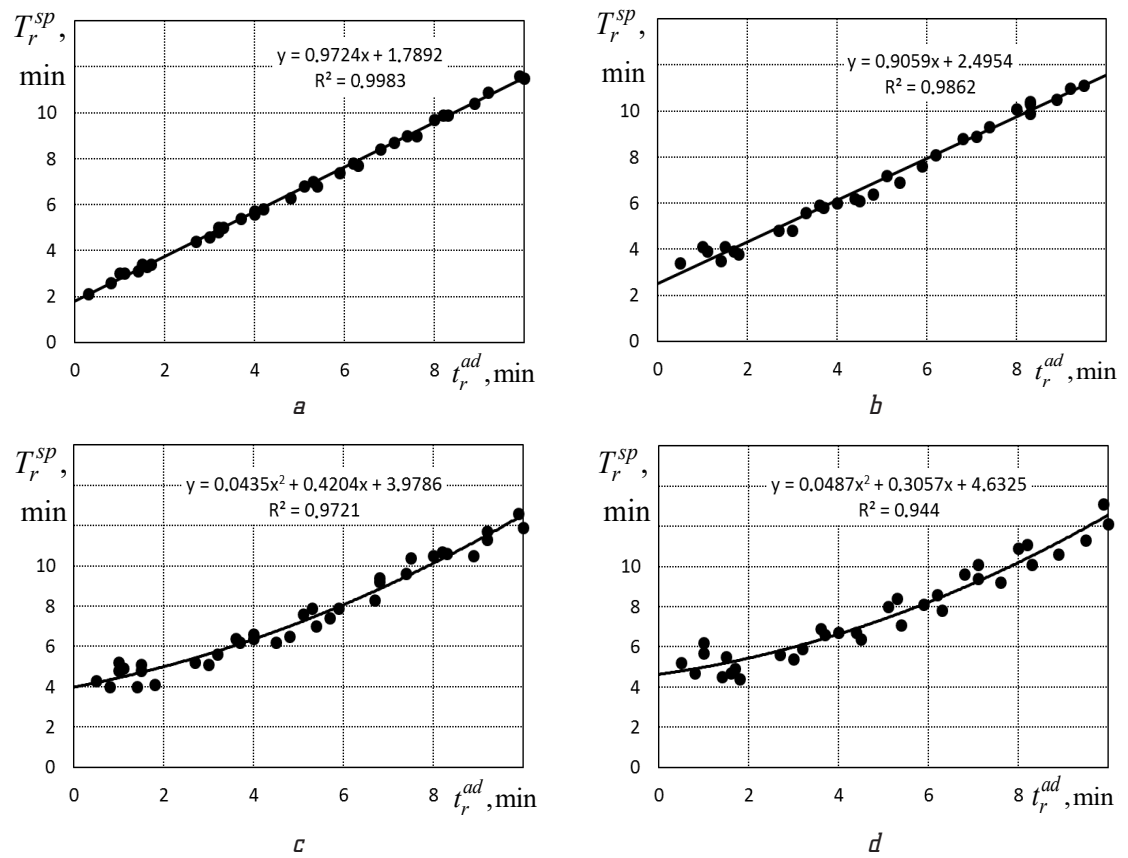

Fig. 2. Influence of service simple service of passengers in the transport interchange hub "Heroiv Pratsi» station: $a$ - the volume of the scheduled transfer is 3 passengers; $b$ - the volume of the scheduled transfer is 8 passengers; $c$ - the volume of the scheduled transfer is 13 passengers; $d$ - the volume of the scheduled transfer is 18 passengers
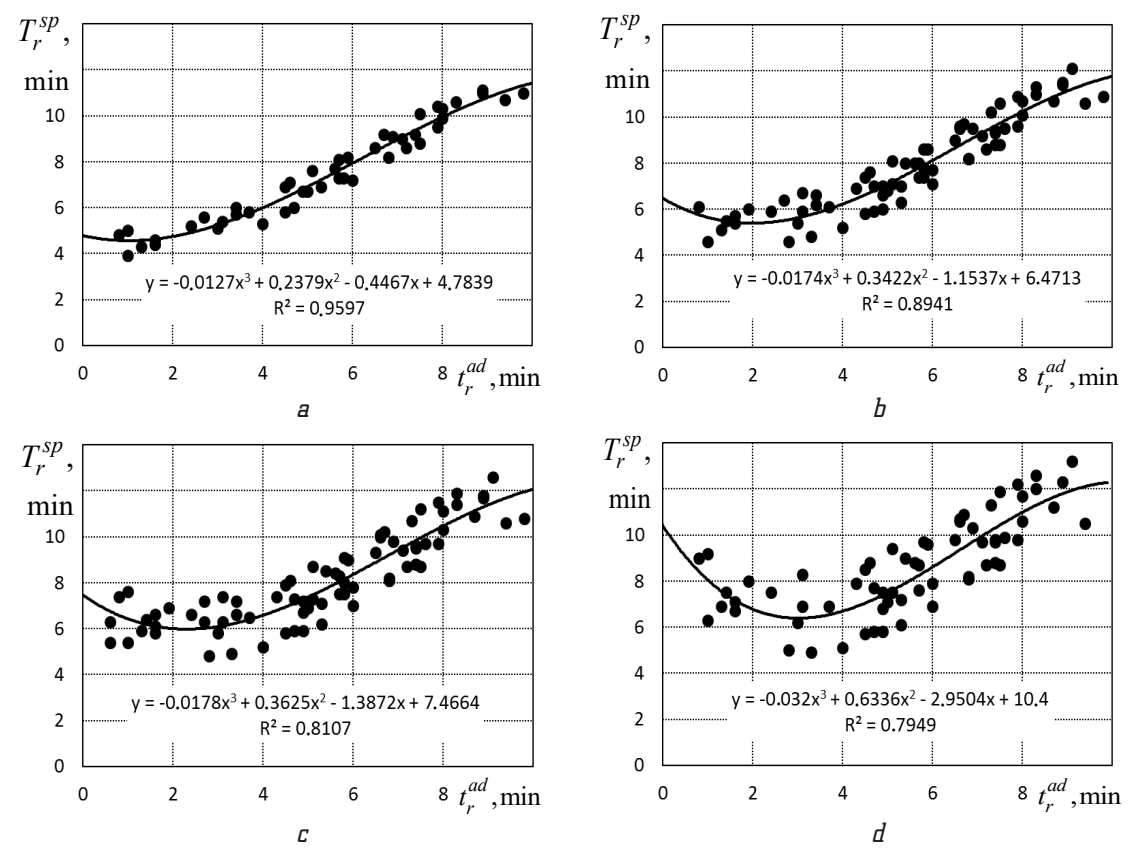

Fig. 3. The impact of service downtime for passengers in the transport hub "Zaliznychna Street» $a$ - the volume of scheduled transfer is 8 passengers; $b$ - the volume of scheduled transfer is 12 passengers; $c$ - the volume of scheduled transfer is 16 passengers; $d$ - the volume of scheduled transfer is 21 passengers
Thus, with a low specific weight of inter-route transfers (up to $40 \%$ ) and small intervals of movement, the introduction of service downtime is an ineffective way to flow subjects in TIH. to 40 passengers and the proportion of inter-route transfers from $30 \%$ (8 pass.) to $77 \%$ (21 pass.), it was found that the impact of the duration of service downtime on the time spent in TIH «Zaliznychna Street» is described by a polynomial of the third degree. The dispersion of values $T_{r}^{s p}$ is greater than in comparison with the routes of TIH «Heroiv Pratsi» station, which indicates an increase in the proportion of inter-route transfer time in the formation of the total duration of the stay of passengers in TIH «ZaliznychnaStreet». Analyzing the established patterns for the routes of TIH «Zaliznychna Street», it can be concluded that the introduction of an additional service downtime is advisable for routes with a specific weight of inter-route transfers of more than $44 \%$ (12 passengers) and at intervals of more than 12 minutes. Under such conditions, it is possible to reduce the time spent by passengers in TIH. At the same time, the duration of service downtime with a specific weight of $44 \%$ (12 pass.) to $59 \%$ (16 pass.) should be from 1 minute up to $3 \mathrm{mi}^{-}$ nutes, and with a specific gravity of over $59 \%$ (16 pass.) - from 2 minutes up to 5 minutes. The introduction of service downtime will make it possible to reduce the time spent by passengers in TIH for the specific weight of inter-route transfers $44 \%$ (12 passengers) by 0.9 minutes $(14 \%)$, for a specific gravity of $59 \%$ (16 pass.) for $1.8 \mathrm{~min}$. (23\%), for a specific gravity of $77 \%$ (21 pass.) for 3.9 minutes (38\%).

\section{Conclusions}

In the course of the study, it was shown that an increase in the synchronization level of inter-route transfers of passengers within the TIH is possible due to the introduction of additional service downtime into the composition of technological operations implemented at stopping points. Establishment of the influence of service downtime of vehicles at a stopping point on the duration of inter-route passenger transfers is implemented using simulation. The methodological basis of the simulation is analytical models for calculating the average time spent by passengers in TIH, based on 
the established base points of time spent by vehicles at stopping points.

On the basis of the simulation of the temporary parameters of the vehicle's stay of typical routes in the TIH «Heroiv Pratsi» station in Kharkiv (50.024616, 36.334937) and TIH «Zaliznychna Street» in Kherson (46.650216, 32.597849), the characteristic patterns of changes in the time spent by passengers in TIH were established. The main factors that affect the feasibility of introducing a service downtime of the vehicle are the volume of scheduled arrival of passengers, the proportion of inter-route transfers and the interval of movement. For routes with scheduled arrivals more than 40 passengers and the specific gravity of interroute transfers up to $45 \%$, the introduction of additional service downtime ineffectively and negatively affects the duration of passengers' stay in TIH. The introduction of service downtime is advisable for routes with an average volume of regular arrivals of passengers (up to 40 passengers) and a specific weight of inter-route transfers of more than $45 \%$. For such conditions, the regularities are described by a third-degree polynomial with the available characteristic period, which minimizes the function of the time spent by passengers. On the basis of the conducted experimental studies, it has been established that for routes with a specific gravity of a change from $45 \%$ to $59 \%$, it is advisable to have a service downtime in the range of 1 minute up to 3 minutes, and for routes with a transfer rate of more than $59 \%$ - within 2 minutes up to $5 \mathrm{~min}$. The use of service downtime will increase the effectiveness of the synchronization of inter-route transfers in conditions of stochastic traffic and reduce the time spent by passengers in the transport interchange hub by 0.9-3.9 minutes (14-38 \%) in comparison with the existing organization of interaction between the subjects of the route flow. Establishing the relationship is a methodological basis for analyzing the impact of vehicle downtime on indicators of the quality of passenger service.

\section{References}

1. Lee, R. J., Sener, I. N. (2016). Transportation planning and quality of life: Where do they intersect? Transport Policy, 48, 146-155. doi: http://doi.org/10.1016/j.tranpol.2016.03.004

2. Wei, Z. H., Cai-Liang, J. (2005). Theoretical analysis of the interchange passengers in urban transport terminals. Journal of Transportation Systems Engineering and Information Technology, 10, 23-30.

3. Vdovychenko, V. (2017). Influence of reserve of carrying capacity of stopping points on the time idle parameters of passenger transport vehicles. Technology Audit and Production Reserves, 1 (2 (39)), 69-75. doi: http://doi.org/10.15587/2312-8372.2018.123604
4. Ferreira, M. C., Fontesz, T., Costa, V., Dias, T. G., Borges, J. L., e Cunha, J. F. (2017). Evaluation of an integrated mobile payment, route planner and social network solution for public transport. Transportation Research Procedia, 24, 189-196. doi: http://doi.org/10.1016/j.trpro.2017.05.107

5. Lipenkov, A. V., Kuzmin, N. A. (2015). Issledovanie poter vremeni ot vzaimnykh pomekh mezhdu avtobusami na ostanovochnykh punktakh. Mir transporta i tekhnologicheskikh mashin, 3, 84-95.

6. Gorbachev, P. F., Makarichev, O. V., Chizhik, V. M. (2013) Waiting time estimation for different methods of route vehicle operation organization. Avtomobilniy transport, 33, 82-86

7. Peña, C., Moreno, E. (2014). Delay at Bus Stops of Transmilenio Transport System According to Parameters Measured «in situ». Case Study Bogotá-Colombia. Procedia - Social and Behavioral Sciences, 160, 121-129. doi: http://doi.org/10.1016/ j.sbspro.2014.12.123

8. Ibarra-Rojas, O. J., López-Irarragorri, F., Rios-Solis, Y. A. (2016). Multiperiod Bus Timetabling. Transportation Science, 50 (3) 805-822. doi: http://doi.org/10.1287/trsc.2014.0578

9. Fouilhoux, P., Ibarra-Rojas, O. J., Kedad-Sidhoum, S., RiosSolis, Y. A. (2016). Valid inequalities for the synchronization bus timetabling problem. European Journal of Operational Research, 251 (2), 442-450. doi: http://doi.org/10.1016/j.ejor.2015.12.006

10. Vdovichenko, V. O. (2017). Slot coordination ofmotion of urban public passenger transport in the conditions oftransport-transplantation terminal. Visnyk KrNU imeni Mykhaila Ostrohradskoho, 5 (106), 51-55.

11. Bezuhlyi, A., Vyrozhemskyi, V., Voloshyna, I., Holovko, S., Lytvynenko, A., Nahaichuk, V., Hameliak, I. (2018). DBN V. 2.3-5: 2018. Vulytsi ta dorohy naselenykh punktiv. Available at: http://online.budstandart.com/ua/catalog/doc-page.html?id doc $=77079$

12. Bolkovska, A., Petuhova, J. (2017). Simulation-based Public Transport Multi-modal Hub Analysis and Planning. Procedia Computer Science, 104, 530-538. doi: http://doi.org/10.1016/ j.procs.2017.01.169

13. Safronov, K. E., Safronov, E. A. (2019). Modelirovanie passazhirskikh i transportnykh potokov v gorodskoy aglomeratsii. Vestnik Moskovskogo avtomobilno-dorozhnogo gosudarstvennogo tekhnicheskogo universiteta (MADI), 3, 75-82.

Andrii Markeoych, PhD, Associate Professor, Lanzhou Jiaotong University, Lanzhou, China, e-mail: andrii.markevych@gmail.com, ORCID: https://orcid.org/0000-0001-7464-5862

Volodymyr Vdovychenko, Doctor of Technical Sciences, Associate Professor, Department of Transport Technology, Kharkio National Automobile and Highway University, Kharkiv, Ukraine, e-mail:Vval2301@gmail.com, ORCID: https://orcid.org/0000-00032746-8175

Igor Ivanov, PhD, Associate Professor, Department of Transport Technology, Kharkiv National Automobile and Highway University, Kharkiv,Ukraine, e-mail: zpavtotrance@ukr.net, ORCID: https:// orcid.org/0000-0002-0336-6513 